\title{
Optimization of enzymatic esterification of dihydrocaffeic acid with hexanol in ionic liquid using response surface methodology
}

\author{
Somayeh Gholivand ${ }^{1}$, Ola Lasekan ${ }^{*}$, Chin Ping Tan ${ }^{1}$, Faridah Abas $^{2}$ and Leong Sze Wei ${ }^{3}$
}

\begin{abstract}
Background: Developing an efficient lipophilization reaction system for phenolic derivatives could enhance their applications in food processing. Low solubility of phenolic acids reduces the efficiency of phenolic derivatives in most benign enzyme solvents. The conversion of phenolic acids through esterification alters their solubility and enhances their use as food antioxidant additives as well as their application in cosmetics.

Results: This study has shown that lipase-catalyzed esterification of dihydrocaffeic acid with hexanol in ionic liquid (1-butyl-3-methylimidazoliumbis (trifluoromethylsulfonyl) imide) was the best approach for esterification reaction. In order to achieve the maximum yield, the process was optimized by response surface methodology (RSM) based on a five-level and four independent variables such as: dosage of enzyme; hexanol/dihydrocaffeic acid mole ratio; temperature and reaction time. The optimum esterification condition $(Y=84.4 \%)$ was predicted to be obtained at temperature of $39.4^{\circ} \mathrm{C}$, time of $77.5 \mathrm{~h}$ dosage of enzyme at $41.6 \%$ and hexanol/dihydrocaffeic acid mole ratio of 2.1 .

Conclusion: Finally, this study has produced an efficient enzymatic esterification method for the preparation of hexyl dihydrocaffeate in vitro using a lipase in an ionic liquid system. Concentration of hexanol was the most significant $(p<0.05)$ independent variable that influenced the yield of hexyl dihydrocaffeate.
\end{abstract}

Keywords: Enzymatic esterification, Hexyl dihydrocaffeate, Candida antartica lipase (Novozyme 435), Ionic liquid, Response surface methodology (RSM)

\section{Background}

Due to the useful biological properties of phenolic acids, they have been reported to have widespread applications in the pharmaceutical, cosmetics and food industries [1-5]. Phenolic acids are compounds which act as hydrogen donors, singlet oxygen quenchers and reducing agents [6]; therefore, they are classified as antioxidants. Anti-atherosclerotic, anti-cancer or anti-carcinogenic, anti-mutagenic, anti-viral, anti-bacterial and anti-inflammatory activities are the other important properties of many phenolic compounds [7]. Most of the phenolic acids are hydrophilic compounds; thus, they exhibit low solubility and stability in oil-based formulae which

\footnotetext{
*Correspondence: olaniny56@gmail.com

1 Department of Food Technology, University Putra Malaysia,

43400 Serdang, Selangor, Malaysia

Full list of author information is available at the end of the article
}

has restricted their application in various industries [2]. However, to apply naturally occurring phenolic acids in oil-based formulation and food processing, the esterification strategy of their carboxylic acid group with suitable aliphatic alcohol is necessary.

The conversion of phenolic acids through esterification alters their solubility and enhances their use as food antioxidant additives as well as their application in cosmetics. phenolic acids trans-esterification with chemical method reduces their product yield since they are heat sensitive and susceptible to oxidation under certain $\mathrm{pH}$ [8]. Therefore, lipase-catalyzed reaction in organic solvent media under mild conditions can be used as an alternative synthetic method. In spite of improving the conversion yield by this method, the existence of a few technical difficulties during the enzyme-catalyzed esterification of phenolic acids has been noticed such as their low solubility 
in the presence of some organic solvent media (e.g. in hexane) where the enzyme is active or reversed behavior in other solvents (e.g. DMSO). Hence, to overcome the above problems, the other suitable synthetic pathway is needed. Ionic liquids have been introduced as a green synthesis media, instead of organic solvents, for the enzymatic transformation of various substances [9].

Ionic liquids (ILs) which are made from bulky cation and a small anion, have been classified as tunable designer solvents with very low volatility and high thermal stability [10]. These solvents have attracted the attention of organic researchers as greener replacements to conventional organic media in order to facilitate sustainable chemistry. The low toxicity of some of the ionic liquids $[11,12]$, reusability, ecofriendly nature of ionic liquids and also their ability to improve the enzyme stability and selectivity are the other advantages of ILs for the bio-catalytic modification of phenolic compounds [13-17]. Several groups have also reported the use of ionic liquids for the enzymatic transformation of flavonoid [9], glucose [18], phenolic glycosides and other compounds [19-22].

In the present study, the enzymatic esterification of dihydrocaffeic acid (DHCA) with 1- hexanol (Fig. 1) as a model reaction was carried out in ionic liquid [1-butyl-3-methylimidazoliumbis (trifluoromethylsulfonyl) imide]. DHCA is a degradation product of caffeic acid with potent antioxidant properties [2]. In fact, it is formed by human intestinal bacteria as hydrogenated analogue metabolite of caffeic acid and eriocitrin [23]. To assist the enzymatic esterification reaction between DHCA and hexanol, response surface methodology (RSM) was used to investigate the reaction processes and

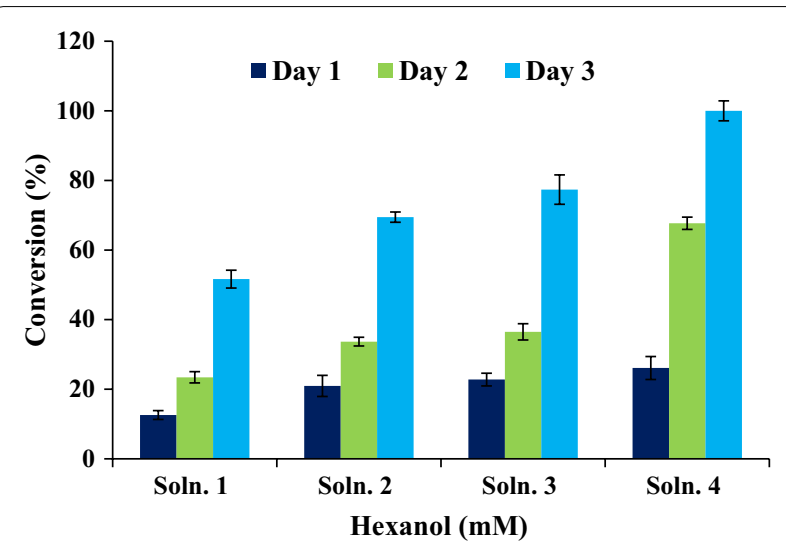

Fig. 1 Esterification of DHCA in 1-3 days by varying molar ratio of dihydrocaffeic acid to hexanol: solution 1 (1:2), solution 2 (1:4), solution 3 (1:8) and solution 4 (1:16) keeping all other parameters constant [at temperature $55^{\circ} \mathrm{C}$ and $250 \mathrm{rpm}$ in ionic liquid (1-butyl-3 methylimidazolium)bis (trifluoromethylsulfonyl) imide] elucidate the relationships between the optimized factors (substrate concentration; dosage of the enzyme, reaction time and temperature) on the degree of esterification as a response variable. RSM is a valuable tool used to determine the optimum levels of two or more treatment variables. In addition; RSM is a useful approach for reducing the experimental runs, time and cost in comparison with one factor at a time for hexyl dihydrocaffeate production. It has important applications in the design, development and formulation of new products, as well as in the improvement of existing product design [24].

\section{Results and discussion \\ Effect of hexanol concentration on the conversion yield of hexyl dihydrocaffeate}

Results of the esterification of DHCA during a 3 days period are shown in Fig. 1. Increasing the hexanol concentration resulted in higher conversion of DHCA to its hexyl ester. Nearly $100 \%$ conversion yield was obtained when the DHCA to hexanol mole ratio of 1:16 was used for 3 days. Although using high dosage of alcohol was particularly useful for obtaining a higher conversion yield for the antioxidant (hexyl dihydrocaffeate) but its separation and purification from the residual unreacted alcohol in solutions containing the DHCA/hexanol mole ratio greater than 1:2 posed serious problems. Therefore, the synthesis of the hexyl dihydrocaffeate was carried out in solutions containing lower DHCA/alcohol ratio (i.e. less than 1:2 ratio) in order to overcome the above drawback. This range of acid/alcohol mole ratio (less than 1:2) was used for optimization of esterification.

To perform the reaction at high temperatures, Novozyme 435 was selected as one of the thermo stable immobilized enzymes since it has optimum reaction temperature of $40-60^{\circ} \mathrm{C}$ and a longer half time [25]. Higher temperature not only decreases the system viscosity which increases the mass transfer [26] but also improves the kinetics of enzymatic reaction which resulted in higher conversion yield. Selection of the suitable range for all factors affecting the conversion of DHCA was based on either the preliminary experiments or literature data [27].

\section{Fitting the response surface model}

Multivariate regression analysis was performed using response surface analysis to fit the mathematical model to the experimental values aiming at high composite desirability and optimal region for the response variable studied, to describe the relationship between four factors and response variable and finally determine the optimum conditions for the synthesis of the natural antioxidant in ionic liquid system. The response surface analysis permitted the development of an empirical relationship where 
response $(\mathrm{Y})$ was measured as a function of substrate mole ratio $\left(\mathrm{X}_{1}\right)$, enzyme amount $\left(\mathrm{X}_{2}\right)$, reaction time $\left(\mathrm{X}_{3}\right)$, reaction temperature $\left(\mathrm{X}_{4}\right)$ and also predicted as the sum of constant $\left(\beta_{0}\right)$, four first-order effects (linear terms in $\mathrm{X}_{1}, \mathrm{X}_{2}, \mathrm{X}_{3}$ and $\mathrm{X}_{4}$ ), four second-order effects (quadratic terms in $X_{1}^{2}, X_{2}^{2}, X_{3}^{2}$ and $X_{4}^{2}$ ) and four interaction effects (interactive terms in $\mathrm{X}_{1} \mathrm{X}_{2}, \mathrm{X}_{1} \mathrm{X}_{3}, \mathrm{X}_{1} \mathrm{X}_{4}$ and $\mathrm{X}_{2} \mathrm{X}_{4}$ ). The results of the analysis of variance revealed a "goodness of fit". In the reduced model, only statistical significant $(\mathrm{p}<0.05)$ terms were included.

The fitted quadratic regression (1), illustrating the degree of conversion of DHCA to its ester as a function of four factors, was determined as follows:

$$
\begin{aligned}
\mathbf{Y}= & -300.110+18.654 \mathbf{X}_{\mathbf{1}}+3.831 \mathbf{X}_{\mathbf{2}}+1.182 \mathbf{X}_{\mathbf{3}} \\
& +8.425 \mathbf{X}_{\mathbf{4}}-1.409 \mathbf{X}_{\mathbf{1}}^{2}-0.052 \mathbf{X}_{\mathbf{2}}^{2}-0.011 \mathbf{X}_{\mathbf{3}}^{\mathbf{2}} \\
& -0.065 \mathbf{X}_{\mathbf{4}}^{2}+0.249 \mathbf{X}_{\mathbf{1}} \mathbf{X}_{\mathbf{2}}+0.058 \mathbf{X}_{\mathbf{1}} \mathbf{X}_{\mathbf{3}} \\
& -0.182 \mathbf{X}_{\mathbf{1}} \mathbf{X}_{\mathbf{4}}-0.038 \mathbf{X}_{\mathbf{2}} \mathbf{X}_{\mathbf{4}}
\end{aligned}
$$

According to the results given in Eq. 1, the model obtained for the response variable described the linear, quadratic and interaction effects of four independent variables affecting the yield. The predicted regression coefficient of adjusted model along with its lack of fit test, $R^{2}$ adjusted and $R^{2}$ value is presented in Table 1 . The final

\begin{tabular}{|c|c|c|c|c|c|}
\hline Sl. no. & Terms & $P_{\text {value }}{ }^{a}$ & F ratio & $\begin{array}{l}\text { Regression } \\
\text { coefficient }\end{array}$ & Response \\
\hline 1 & Constant & & - & $\beta_{0}$ & -300.110 \\
\hline 2 & $x_{1}$ & 0.000 & 29.06 & $\beta_{1}$ & 18.654 \\
\hline 3 & $x_{2}$ & 0.007 & 9.84 & $\beta_{2}$ & 3.831 \\
\hline 4 & $x_{3}$ & 0.002 & 14.65 & $\beta_{3}$ & 1.182 \\
\hline 5 & $x_{4}$ & 0.000 & 22.91 & $\beta_{4}$ & 8.425 \\
\hline 6 & $X_{1}^{2}$ & 0.000 & 83.20 & $\beta_{12}$ & -1.409 \\
\hline 7 & $x_{2}^{2}$ & 0.007 & 9.64 & $\beta_{22}$ & -0.052 \\
\hline 8 & $x_{3}^{2}$ & 0.002 & 14.56 & $\beta_{32}$ & -0.011 \\
\hline 9 & $x_{4}^{2}$ & 0.001 & 15.01 & $\beta_{42}$ & -0.065 \\
\hline 10 & $x_{1} x_{2}$ & 0.000 & 24.52 & $\beta_{12}$ & 0.249 \\
\hline 11 & $x_{1} x_{3}$ & 0.015 & 7.63 & $\beta_{13}$ & 0.058 \\
\hline 12 & $X_{1} X_{4}$ & 0.003 & 13.12 & $\beta_{14}$ & -0.182 \\
\hline 13 & $x_{2} x_{4}$ & 0.036 & 5.34 & $\beta_{24}$ & -0.038 \\
\hline$R^{2}$ & & & & & 0.95 \\
\hline$R^{2}$ (adj) & & & & & 0.91 \\
\hline ( $p$ value) & & & & & $0.000^{\mathrm{a}}$ \\
\hline (F value) & & & & & 51.26 \\
\hline
\end{tabular}
reduced model which has been fitted based on $\mathrm{F}$ test at

Table 1 ANOVA and regression coefficient of the first and second degree polynomial regression model

Concentration of hexanol $\left(\times 10^{-4} \mathrm{mM}\right) \mathrm{X}_{1}$, enzyme amount (\%) $\mathrm{X}_{2}$, reaction time (h) $\mathrm{X}_{3}$ and reaction temperature $\mathrm{X}_{4}$

a Significant $(p<0.05)$ the $5 \%$ confidence level of the regression model $(\mathrm{p}<0.05)$ resulted in a second-order polynomial model for the response variable studied. It should be noted that the full quadratic equation was fitted for predicting the degree of esterification value.

The unity of the $\mathrm{R}^{2}$ value means that the model is strong and also has a better prediction of the response [28]. On the other, the coefficient of determination $\left(R^{2}\right)$ provided the quality and satisfactory fit to the second-order polynomial model. It has been reported that for the model to have goodness of fit (predicted response variables), the $\mathrm{R}^{2}$ should be greater than 0.80 [29]. In the current study, the high values of $R^{2}$ adjusted (0.91) and $R^{2}(0.95)$ indicated the high variability in the response variable studied and high significance in model respectively, and as a result, these guaranteed an adequate fitting of the polynomial model to the experimental data. Also, the lack of fit ( $F$ value), which measures the fitness of models, resulted in no significant $F$ value ( $>0.05$ ) in terms of the response variables studied.

In addition, Table 1 shows that the linear terms of the four independent variables had significant positive effects on conversion while at the same time indicating a negative effect on the quadratic terms. Interaction effects between two factors namely: hexanol-enzyme and hexanol-time were positively related to the percent of conversion value. Conversely, response value was negatively influenced by interaction between hexanol-temperature and enzyme-temperature. These significant terms should be considered as the primary independent variables for evaluating the variation of conversion yield.

In accordance with Table 1, the most significant independent factor affecting the variation of conversion yield was found in the quadratic term for concentration of hexanol. Furthermore, the probability (p) of the regression model (0.000) confirmed that the model was highly significant for the response variable. Also, Table 1 clearly revealed that the esterification of dihydrocaffeic acid as a response variable was significantly $(p<0.05)$ influenced by the linear and quadratic terms of all studied factors, followed by the interaction effects of hexanol-enzyme, hexanol-time, hexanol-temperature and enzyme-temperature variables.

\section{Optimization procedure}

Graphical and numerical optimization procedures were employed to predict the precise level of four factors resulting in the desirable goal of response variable. An optimal treatment was shown by response surface plotting of the values. Using 3D response surface of the regression model for the graphical interpretation of the factor interactions has been highly recommended [30-32]. 
Figure 2 indicated the three-dimensional (3D) response surface for two factors at a constant value of the other two factors. The 3D diagrams can be used to better understand the significant $(p<0.05)$ interaction effect between two independent variables and response as well as locate their optimum levels. As it is evident from the surface plots ( $a, b, c$ and d), by increasing the concentration of hexanol, the response variable (hexyl dihydrocaffeate) increased. Further increase in hexanol concentration $(>6 \mathrm{mM})$ significantly decreased the percent conversion of hexyl dihydrocaffeic acid (HDHCA). Also the conversion yield was increased with increased enzyme amount, time and temperature up to $40{ }^{\circ} \mathrm{C}$.

The response optimizer was employed to generate the optimal set of four factors leading to the desired criteria of response variable. The conversion of dihydrocaffeic acid would be viewed as an optimal product if the goal employed for numerical or graphical optimization led to a maximum degree of esterification. The optimum esterification conditions were predicted to be obtained at temperature of $39.4{ }^{\circ} \mathrm{C}$, time of $77.5 \mathrm{~h}$ dosage of enzyme at
$41.6 \%$ and concentration of hexanol at $9.3 \times 10^{-4} \mathrm{mM}$ using response optimizer and response surface plots. As it can be seen in Fig. 3, the composite and the individual desirability for the degree of esterification of phenolic compound (dihydrocaffeic acid) were found to be one.

\section{Model verification}

Comparison was made between the experimental data of the response and the fitted values predicted by the response regression model (Table 2) using two-sample $\mathrm{T}$ test for checking the adequacy of the response surface equation. The results exhibited no significant $(p>0.05)$ difference between the predicted data and actual values. Proximity of the observed values and predicted data and also the high correlation coefficient (0.95) affirmed that the corresponding response surface model was adequate in predicting variations of response variable as a function of esterification conditions. However, the close results of the predicted and experimental values under the optimum area revealed the appropriateness of the model.

a Surface Plot of Conversion (\%) vs Time (h) and Hexanol (mM)

b Surface Plot of Conversion (\%) vs Enzyme (\%) and Hexanol (mM)
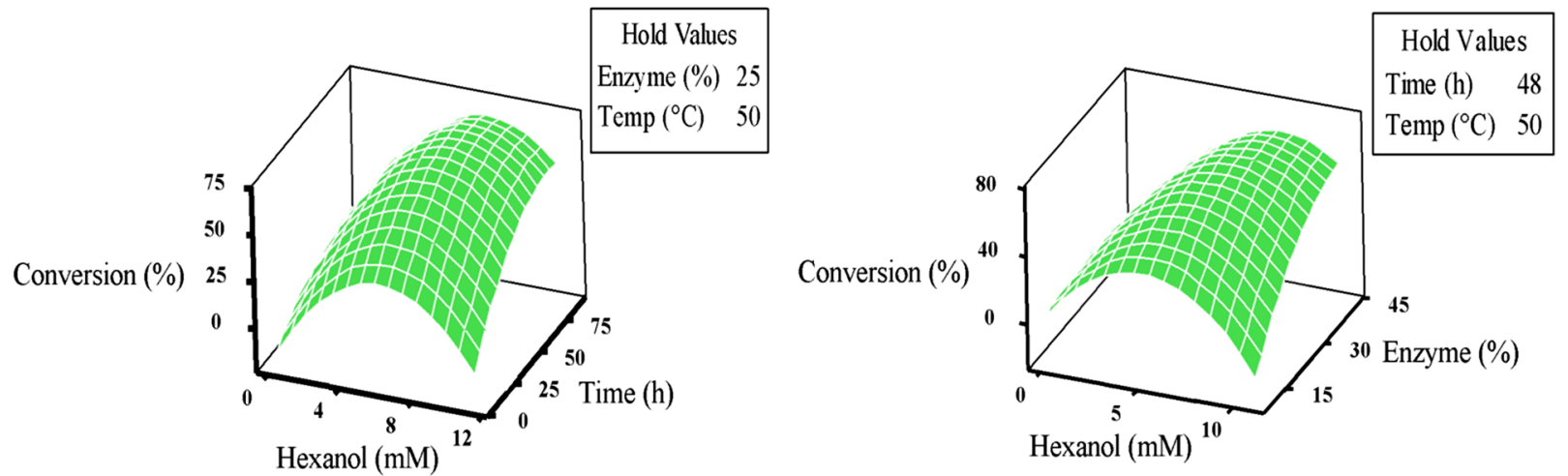

c

Surface Plot of Conversion $(\%)$ vs Temp $\left({ }^{\circ} \mathrm{C}\right)$ and Hexanol $(\mathrm{mM})$

d Surface Plot of Conversion $(\%)$ vs Temp $\left({ }^{\circ} \mathrm{C}\right)$ and Enzyme $(\%)$
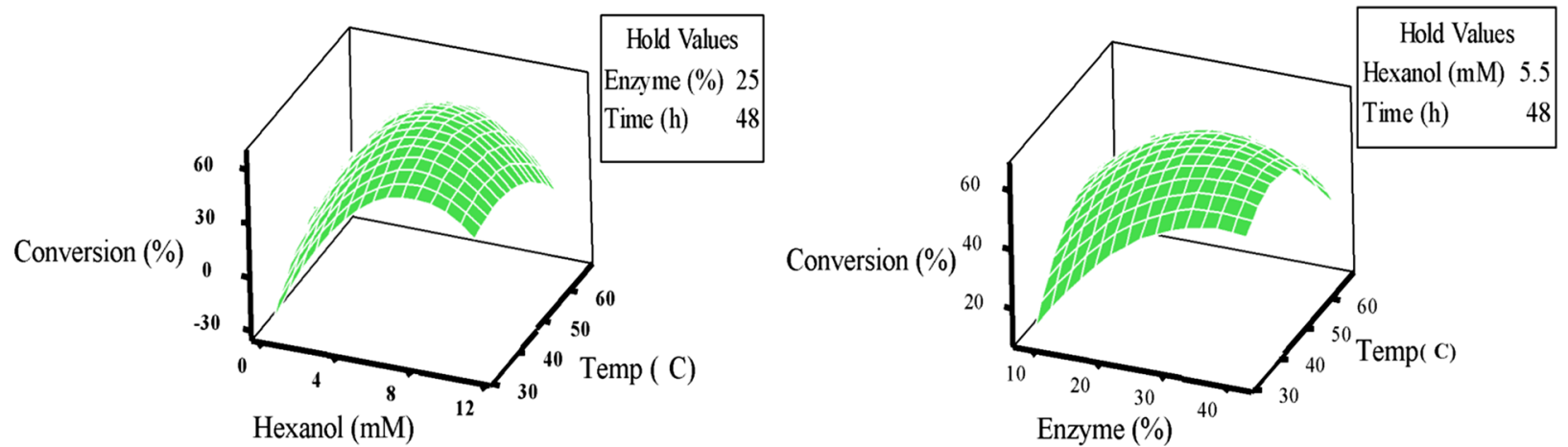

Fig. 2 Three-dimensional response surface plots (a-d) of the conversion of dihydrocaffeic acid to hexyl dihydrocaffeate 


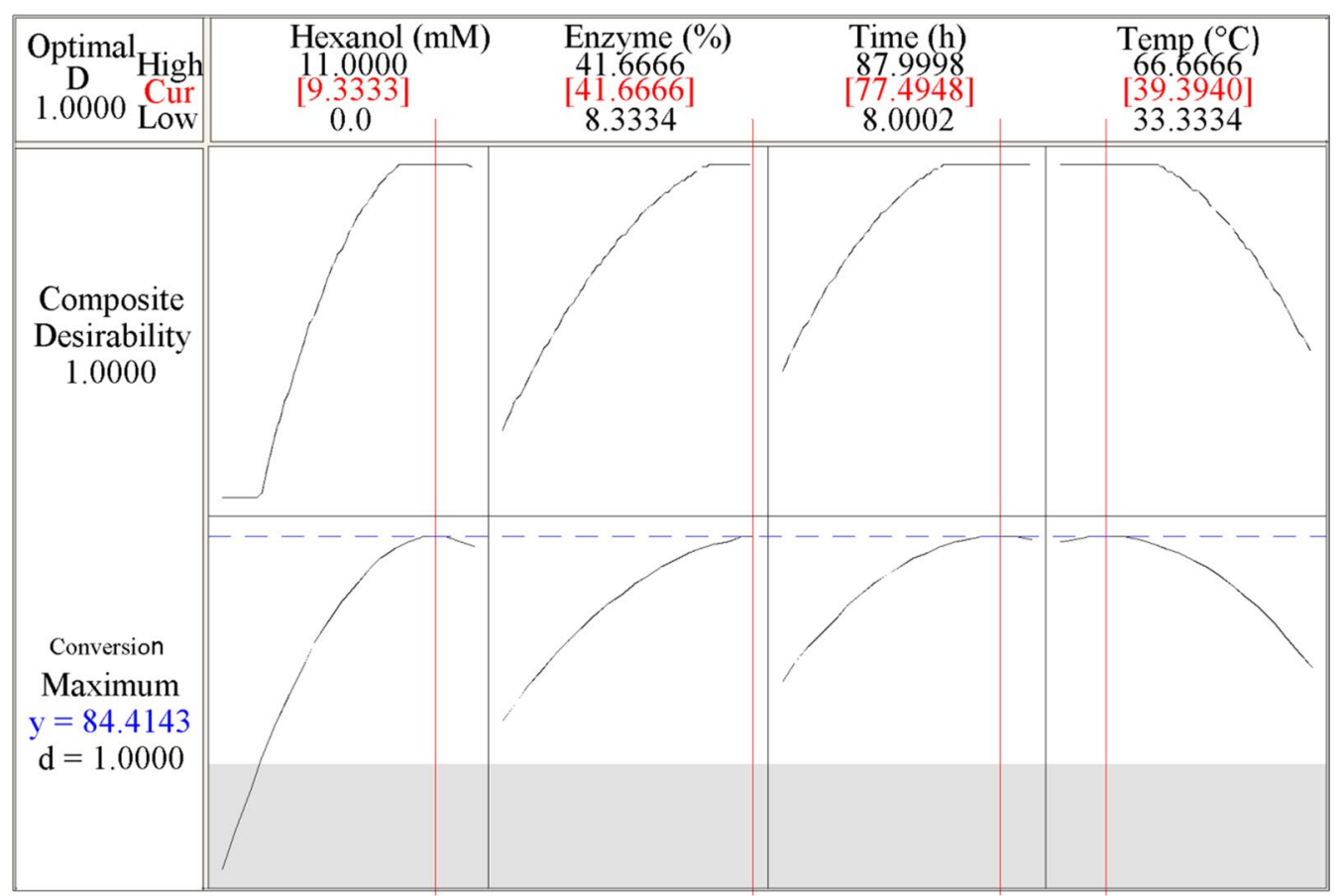

Fig. 3 Numerical response optimizer

\section{Characterization of the purified product FTIR analysis for hexyl dihydrocaffeate}

The results of the hexyl dihydrocaffeate FTIR with spectrum in the $4000-280 \mathrm{~cm}^{-1}$ regions are presented in Table 3 . The bands at $3385-3502 \mathrm{~cm}^{-1}$ could be attributable to the stretching of the hydroxyl functional group of catechol moiety. The adsorption bands at about $2900 \mathrm{~cm}^{-1}$ with two branches can be attributed to the $\mathrm{C}=\mathrm{H}$ stretching of aromatic and aliphatic, while the peak at $1704 \mathrm{~cm}^{-1}$ was assigned to $\mathrm{C}=\mathrm{O}$ stretching of the ester. The bands found at wavelengths lower than $1608 \mathrm{~cm}^{-1}$ revealed the presence of aromatic ring in the structure of the resultant ester. Also, the bands between 1261 and 1008 are related to $\mathrm{C}-\mathrm{O}$ stretching of the ester (Table 3).

\section{NMR analysis for hexyl dihydrocaffeate and other alkyl esters} The synthesized antioxidant ester (hexyl dihydrocaffeate) was identified by $1 \mathrm{H}$ NMR $(500 \mathrm{MHz}$, (METHANOL-d4)) and its result is presented in Fig. 4. Chemical shifts $(\delta)$ were given in ppm while coupling constants were in $\mathrm{Hz}$. The result of the ester is: ${ }^{1} \mathrm{H}$ NMR $\delta$ ppm: $0.90(\mathrm{t}, \mathrm{J}=6.99 \mathrm{~Hz}, 3 \mathrm{H}), 1.20-1.36(\mathrm{~m}, 6 \mathrm{H})$, $1.50-1.62(\mathrm{~m}, 2 \mathrm{H}), 2.54(\mathrm{t}, \mathrm{J}=7.57 \mathrm{~Hz}, 2 \mathrm{H}), 2.75(\mathrm{t}$, $\mathrm{J}=7.60 \mathrm{~Hz}, 2 \mathrm{H}), 4.03(\mathrm{t}, \mathrm{J}=6.70 \mathrm{~Hz}, 2 \mathrm{H}), 6.49(\mathrm{dd}$, $\mathrm{J}=8.15,1.75 \mathrm{~Hz}, 1 \mathrm{H}), 6.62(\mathrm{~d}, \mathrm{~J}=1.75 \mathrm{~Hz}, 1 \mathrm{H}), 6.65$ $(\mathrm{d}, \mathrm{J}=8.15 \mathrm{~Hz}, 1 \mathrm{H})$.

\section{Conclusion}

The central composite design (CCD) was shown to be a valuable tool for optimizing the esterification conditions of dihydrocaffeic acid. Concentration of hexanol was the most significant $(\mathrm{p}<0.05)$ independent variable affecting the conversion yield. Results have shown that hexyl dihydrocaffeate yield was significantly $(\mathrm{p}<0.05)$ affected by the linear and quadratic terms of all the factors studied. Moreover, the optimization procedure showed that the optimum region with the highest desirability $(D=1)$ was achieved at temperature of $39.4{ }^{\circ} \mathrm{C}$, time of $77.5 \mathrm{~h}$ dosage of enzyme at $41.6 \%$ and concentration of hexanol at $9.3 \times 10^{-4} \mathrm{mM}$.

\section{Experimental Materials}

Ionic liquids consisting: 1-butyl-3-methylimidazoliumbis (trifluoromethylsulfonyl) imide with purity of $98 \%$ was acquired from Sigma-Aldrich (Milan, Italy). Immobilized lipase (triacylglycerol hydrolase, EC 3.1.1.3; Novozyme 435 from C.antarctica supported on acrylic resin beads was obtained from Novo Nordisk Bio-industrials, Inc. (Bagsvaerd, Denmark). 3,4 Dihydroxycaffeic acid (DHCA), hexanol, and methanol with the highest available purity purchased from Sigma-Aldrich (Milan, Italy). $3 \AA$ A molecular sieves (10-20 Mesh beads) were obtained from Fluka (Fluka, Neu-Ulm, Germany). Chloroform, diethyl ether and all solvents were of analytical and HPLC 
Table 2 Central composite design: factor $\left(X_{i}\right)$, response variable $(Y)$ and residual

\begin{tabular}{|c|c|c|c|c|c|c|c|}
\hline \multirow[t]{2}{*}{ Run } & \multirow{2}{*}{$\begin{array}{l}\text { Concentration of hexanol } \\
\left(\mathrm{mM} \times 10^{-4}\right) \\
\mathrm{X}_{1}\end{array}$} & \multirow{2}{*}{$\begin{array}{l}\text { Enzyme } \\
\text { amount }^{\mathrm{b}}(\%) \\
\mathrm{X}_{2}\end{array}$} & \multirow{2}{*}{$\begin{array}{l}\text { Reaction time } \\
\text { (h) } \\
X_{3}\end{array}$} & \multirow{2}{*}{$\begin{array}{l}\text { Reaction tempera- } \\
\text { ture }\left({ }^{\circ} \mathrm{C}\right) \\
\mathrm{X}_{4}\end{array}$} & \multirow{2}{*}{$\begin{array}{l}\text { Conversion (\%) } \\
\mathrm{Y}\end{array}$} & \multirow{2}{*}{$\begin{array}{l}\text { Predicted (\%) } \\
Y_{0}\end{array}$} & \multirow{2}{*}{$\begin{array}{l}\text { Residua } \\
\mathrm{Y}-\mathrm{Y}_{0}\end{array}$} \\
\hline & & & & & & & \\
\hline $12^{c}$ & $5.5(0)$ & $25.0(0)$ & $48.0(0)$ & $50.0(0)$ & 65.131 & 62.222 & 2.909 \\
\hline 11 & $8.8(+1)$ & $35.0(+1)$ & $24.0(-1)$ & $60.0(+1)$ & 25.054 & 28.459 & -3.404 \\
\hline 4 & $2.2(-1)$ & $15.0(-1)$ & $24.0(-1)$ & $60.0(+1)$ & 17.151 & 23.714 & -6.563 \\
\hline 23 & $2.2(-1)$ & $15.0(-1)$ & $72.0(+1)$ & $40.0(-1)$ & 12.597 & 16.561 & -3.964 \\
\hline 5 & $2.2(-1)$ & $35.0(+1)$ & $24.0(-1)$ & $40.0(-1)$ & 18.375 & 9.751 & 8.623 \\
\hline 26 & $8.8(+1)$ & $15.0(-1)$ & $72.0(+1)$ & $60.0(+1)$ & 29.213 & 36.068 & -6.855 \\
\hline 3 & $8.8(+1)$ & $35.0(+1)$ & $72.0(+1)$ & $40.0(-1)$ & 81.140 & 78.966 & 2.174 \\
\hline $14^{c}$ & $5.5(0)$ & $25.0(0)$ & $48.0(0)$ & $50.0(0)$ & 64.554 & 62.222 & 2.332 \\
\hline 1 & $2.2(-1)$ & $35.0(+1)$ & $72.0(+1)$ & $60.0(+1)$ & 19.431 & 24.580 & -5.149 \\
\hline 19 & $8.8(+1)$ & $15.0(-1)$ & $24.0(-1)$ & $40.0(-1)$ & 21.519 & 11.621 & 9.897 \\
\hline 6 & $5.5(0)$ & $25.0(0)$ & $8.0(-1.66)$ & $50.0(0)$ & 17.720 & 25.369 & -7.649 \\
\hline 25 & $11.0(1.66)$ & $25.0(0)$ & $48.0(0)$ & $50.0(0)$ & 35.044 & 34.562 & 0.482 \\
\hline $13^{c}$ & $5.5(0)$ & $25.0(0)$ & $48.0(0)$ & $50.0(0)$ & 62.571 & 60.415 & 2.156 \\
\hline $28^{c}$ & $5(0)$ & $25.0(0)$ & $48.0(0)$ & $50.0(0)$ & 60.401 & 60.415 & -0.014 \\
\hline 22 & $5.5(0)$ & $8.3(-1.66)$ & $48.0(0)$ & $50.0(0)$ & 35.341 & 34.698 & 0.643 \\
\hline 7 & $5.5(0)$ & $25.0(0)$ & $87.9(1.66)$ & $50.0(0)$ & 66.911 & 59.798 & 7.113 \\
\hline 20 & $5.5(0)$ & $41.6(1.66)$ & $48.0(0)$ & $50.0(0)$ & 55.932 & 57.111 & -1.179 \\
\hline 15 & $5.5(0)$ & $25.0(0)$ & $48.0(0)$ & $66.6(1.66)$ & 45.865 & 41.460 & 4.405 \\
\hline 27 & $0.0(-1.66)$ & $25.0(0)$ & $48.0(0)$ & $50.0(0)$ & 0.000 & 1.018 & -1.018 \\
\hline 9 & $5.5(0)$ & $25.0(0)$ & $48.0(0)$ & $33.3(-1.66)$ & 38.220 & 43.160 & -4.94 \\
\hline 30 & $2.2(-1)$ & $35.0(+1)$ & $24.0(-1)$ & $60.0(+1)$ & 21.574 & 20.005 & 1.569 \\
\hline 2 & $8.8(+1)$ & $15.0(-1)$ & $72.0(+1)$ & $40.0(-1)$ & 42.416 & 48.361 & -5.945 \\
\hline 18 & $8.8(+1)$ & $35.0(+1)$ & $72.0(+1)$ & $60.0(+1)$ & 69.420 & 65.198 & 4.222 \\
\hline 10 & $8.8(+1)$ & $15.0(-1)$ & $24.0(-1)$ & $60.0(+1)$ & 15.065 & 13.174 & 1.891 \\
\hline $29^{c}$ & $5.5(0)$ & $25.0(0)$ & $48.0(0)$ & $50.0(0)$ & 66.363 & 69.144 & -2.781 \\
\hline 16 & $2.2(-1)$ & $35.0(+1)$ & $72.0(+1)$ & $40.0(-1)$ & 24.885 & 28.172 & -3.287 \\
\hline 8 & $2.2(-1)$ & $15.0(-1)$ & $24.0(-1)$ & $40.0(-1)$ & 15.505 & 11.986 & 3.519 \\
\hline 24 & $2.2(-1)$ & $15.0(-1)$ & $72.0(+1)$ & $60.0(+1)$ & 49.382 & 42.135 & 7.247 \\
\hline 17 & $8.8(+1)$ & $35.0(+1)$ & $24.0(-1)$ & $40.0(-1)$ & 53.586 & 56.072 & -2.486 \\
\hline $21^{c}$ & $5.5(0)$ & $25.0(0)$ & $48.0(0)$ & $50.0(0)$ & 65.196 & 69.144 & -3.948 \\
\hline
\end{tabular}

a Substrate molar ratio was selected correspondingly to $0.5-2\left(2.2-8.8 \times 10^{-4} \mathrm{mM}\right)$ hexanol to dihydrocaffeic acid $\left(4.4 \times 10^{-4} \mathrm{mM}\right)$

b $15-35 \%$ relative to the total weight of substrates

c Center point

Table 3 Representative FTIR spectra $\left(\mathrm{cm}^{-1}\right)$ of dihydrocaffeic acid ester

\begin{tabular}{llll}
\hline Frequency range $\left(\mathbf{c m}^{\mathbf{- 1}}\right)$ & \multicolumn{2}{l}{ Frequency $\left(\mathbf{c m}^{-\mathbf{1}}\right)$} & Functional groups \\
\cline { 2 - 4 } & DHCA & Hexyl dihydrocaffeate & \\
\hline $3500-3200$ & 3338 & $3502^{\mathrm{b}}, 3386$ & $\mathrm{O}-\mathrm{H}$ stretching \\
$3000-2850$ & $2925-2869$ & $2917-2856$ & $\mathrm{C}-\mathrm{H}$ stretching \\
$1760-1690$ & 1668 & 1705 & $\mathrm{C}=\mathrm{O}$ stretching \\
$1600-1400$ & $1525-1441$ & $1608-1534$ & $\mathrm{C}=$ C stretching \\
$1320-1000$ & $1207-1286$ & $1192-1261$ & $\mathrm{C}-\mathrm{O}$ stretching \\
$700 \pm 20$ & - & 728 & Long chain (C-H) \\
\hline
\end{tabular}

\footnotetext{
a Dihydrocaffeic acid
}

b H-bond lattice 


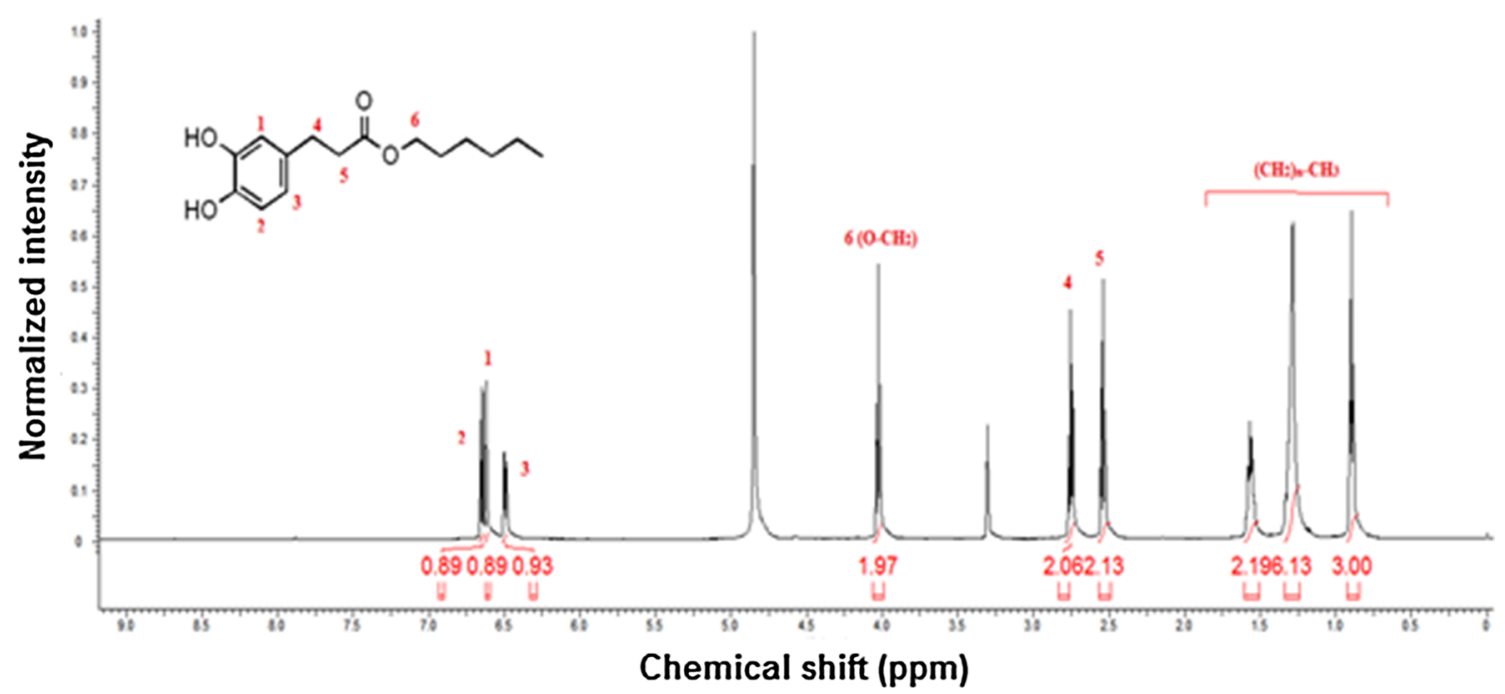

Fig. 4 NMR spectrum of hexyl dihydrocaffeate

grades purchased from Fisher Scientific, Inc. (Slangerup, Denmark). Thin-layer chromatography (TLC) with a silica gel 60F254 plate no. 5715 was obtained from Merck (Darmstadt Germany).

\section{Experimental design}

The effect of four factors [i.e. $\mathrm{X}_{1}$ (dihydrocaffeic acid to hexanol molar ratio of 1:0.5-1:2); $\mathrm{X}_{2}$ (immobilizedenzyme amount $15-35 \%$ by the total weight of substrates); $\mathrm{X}_{3}$ (reaction time of 24-72 h) and $\mathrm{X}_{4}$ (reaction temperature of $40-60^{\circ} \mathrm{C}$ )] were selected for the synthesis of hexyl dihydrocaffeate as a response variable and was assessed using RSM (Table 4). Central composite design (CCD), as a statistical method, was employed to investigate the major and combined effects of all independent variables on the degree of esterification, to generate a model between variables and finally, to evaluate the effect of these parameters in order to optimize the reaction conditions for the synthesis of hexyl dihydrocaffeate enzymatically leading to the desired goal. MINITAB v16 statistical package (Minitab Inc., State College, PA, USA) software was applied for generating experimental design matrix, data analysis and optimization procedure.

As presented in Table 2, 30 experimental runs along with center point which was repeated six times, were assigned using a second order composite design taking into account four independent variables at five levels of each factor [30]. The treatments were randomized in order to reduce the impact of unexplained variability in the actual response owing to extraneous parameters.

\section{Statistical analysis}

Analysis of variance and regression analysis were carried out to determine statistically significant model terms and regression coefficients, fitting of mathematical models to the experimental data aiming at an overall optimal region and high composite desirability for the response variable. Multiple regression coefficients were employed

Table 4 Levels of independent variables established according to central composite design for enzymatic esterification of hexyl dihydrocaffeate condition level (coded and, un coded)

\begin{tabular}{|c|c|c|c|c|c|}
\hline \multirow[t]{2}{*}{ Independent variable } & \multicolumn{5}{|c|}{ Independent variable level } \\
\hline & $\operatorname{Low}(-1)$ & Medium (0) & $\operatorname{High}(+1)$ & Axial (-1.66) & Axial (+1.66) \\
\hline Reaction time ${ }^{a}$ & 24 & 48 & 72 & 8.0 & 88.0 \\
\hline Reaction Temp ${ }^{b}$ & 40 & 50 & 60 & 33.3 & 66.7 \\
\hline Conc. of hexanol ${ }^{c}$ & 2.2 & 5.5 & 8.8 & 0.0 & 11.0 \\
\hline Enzyme amount $^{\mathrm{d}}$ & 15 & 25 & 35 & 8.3 & 41.6 \\
\hline
\end{tabular}

a Reaction time (h)

b Reaction temperature $\left({ }^{\circ} \mathrm{C}\right)$

c Concentration of hexanol (substrate molar ratio was selected correspondingly to $0.5-2\left((2.2-8.8) \times 10^{-4} \mathrm{mM}\right)$ of hexanol to dihydrocaffeic acid $\left(4.4 \times 10^{-4} \mathrm{mM}\right)$

d $15-35 \%$ relative to the total weight of substrates 
by applying the least-squares technology [33] to predict the linear, quadratic polynomial models and also interactive effects between tested parameters for response function. The mathematical relationship among factors and response was expressed in the quadratic polynomial Eq. 2:

$$
Y=\beta_{0}+\sum_{i=1}^{4} \beta_{i} \chi_{i}+\sum_{i=1}^{4} \beta_{i i} \chi_{i}^{2}+\sum_{i=1}^{3} \sum_{j=i+1}^{4} \beta i j x i x j
$$

where: $\mathrm{Y}$ is the predicted response value, $\beta_{0}$ is constant, $\beta i, \beta i i$ and $\beta i j$ are the linear, quadratic and interaction regression coefficients of RSM model, and $\mathrm{Xi}$ and $\mathrm{Xj}$ are the factor variables.

The individual linear, quadratic and interaction effects and also regression coefficients terms of tested parameters were presented by the ANOVA results. According to the F-ratio at P-value of 0.05 ; the significance of the equation parameters for response based on model analysis, coefficient of determination $\left(R^{2}=\right.$ at least 0.80$)$ analysis as outlined and the suitability of the model were evaluated $[29,34,35]$.

\section{Optimization procedure}

The optimization procedure was employed to acquire the optimal levels of four independent variables $\left(\mathrm{X}_{1}, \mathrm{X}_{2}, \mathrm{X}_{3}\right.$ and $\mathrm{X}_{4}$ ) after producing the polynomial regression equation concerning the factors studied. By choosing desired goal for the variable, numerical optimization was performed to evaluate the exact optimum level of factors leading to the desired enzymatic synthesis conditions in terms of percent of dihydrocaffeic acid conversion. Optimum conditions that depended on the factors, were achieved through the predicted equation evaluated using RSM. Moreover, for deducing workable optimal conditions, a graphical technique was applied [36, 37]. Generally, the three-dimensional (3D) response surface plots were employed for visualizing the relationship between experimental levels for each independent variable and the response and also for deducing the optimal conditions [30,38]. In order to interpret graphical interaction of the four factors studied (graphical optimization), the $3 \mathrm{D}$ response surface plots were plotted by altering two variables in the experimental range and keeping the other two variables constant at the center point.

\section{Model verification}

Model validation was done theoretically by comparing the experimental data and predicted values. This was employed to assess the adequacy of the final reduced model equation obtained using two-sample $\mathrm{T}$ test. There must be close agreement between the predicted and experimental values and no significant difference existing for model adequacy validation. Experiments under the suggested optimum conditions were tested to verify the suitability of response model for predicting optimum data as well.

\section{Enzymatic esterification of dihydrocaffeic acid with hexanol in ionic liquid}

The enzymatic esterification of DHCA was performed in ionic liquid (1-buthyl-3-methylimidazoliumbis (trifluoromethylsulfonyl) imide). A fixed amount of DHCA $\left(4.4 \times 10^{-4} \mathrm{mM}\right)$ with different quantities of hexanol, according to the substrate mole ratios presented in Table 2, were introduced into the test tubes which contained various dosages of the powdered $C$. antarctica lipase in ionic liquid as a medium. Typical reactions were conducted in the presence of activated $3 \AA \AA$ molecular sieves as by-product (water) eliminating substance. The reactions were performed in an incubator equipped with a shaker operating at $250 \mathrm{rpm}$, under various temperatures and times (Table 2). With the removal of the biocatalyst, the reaction was terminated and then, quantitative analysis of the synthesized esters was carried out by HPLC.

\section{Ester purification}

The alkyl dihydrocaffeate esters were obtained by extracting each reacted solution in diethyl ether. The ether layer was dried over sodium sulfate and filtered [39]. In each case, the filtrate was evaporated to dryness under reduced pressure. The extract was applied onto a silica gel column $(2.5 \times 30 \mathrm{~cm}$, fractions of $50 \mathrm{~mL})$, which washed with $200 \mathrm{~mL}$ of chloroform (100\%) and $400 \mathrm{~mL}$ of (99:1-98:2\%) chloroform-methanol mixture respectively for eluting the unreacted substrates. The formed ester product was detected by thin-layer chromatography (TLC) [40] or HPLC methods.

\section{Degree of esterification}

The following equation was employed [28] to calculate the degree of esterification from the HPLC profile:

$$
\text { Degree of esterification (\%) }=A_{\text {tpe }} /\left(1: 462 A_{\text {tp }}+A_{\text {tpe }}\right)
$$

where $A_{\text {tp }}$ is the total peak area of dihydrocaffeic acid, $A_{\text {tpe }}$ is the total peak area of hexyl dihydrocaffeate and 1.462 is the ratio of the average molecular weight of hexyl dihydrocaffeate to the average molecular weight of dihydrocaffeic acid.

\section{Characterization of purified product HPLC analysis}

The reaction components were diluted with methanol and filtered using syringe filter $(0.22 \mu \mathrm{m})$. A $10 \mu \mathrm{L}$ aliquot was taken from the reaction mixture and injected 
in HPLC (Agilent 1200 series, Waldbrunn, Germany) equipped with a $\mathrm{C} 18$ reverse-phase capillary column $(250 \times 4.6 \mathrm{~mm}, 5 \mu \mathrm{L})$ as well as an ultraviolet detector at wavelength range of 200-325 which was applied for DHCA evaluation. The injected samples were eluted by mobile phases including: $90 \%$ of solvent $A$ and $10 \%$ of solvent B [namely methanol (pre-dried over $3 \AA$ molecular sieves) and $0.75 \%$ of acetic acid in distilled water respectively] at a flow rate of $1 \mathrm{~mL} / \mathrm{min}$ for $16 \mathrm{~min}$ [41].

\section{Fourier transforms infrared (FTIR) and nuclear magnetic resonance (NMR) analysis}

Fourier transform infrared (FTIR) and nuclear magnetic resonance (NMR) spectroscopy were used for characterization of each alkyl dihydrocaffeate. The functional groups of each synthesized compound were identified by Perkin Elmer spectrum 100 Series spectrometer (United Kingdom) facilitated with a mid-infrared detector-DTGS (deuterated triglycine sulphate). Each synthesized product was dispersed in potassium bromide pellet and compressed into a disc by pressure. Then the IR spectrum of each sample was recorded. The resultant FTIR spectrum in the $4000-280 \mathrm{~cm}^{-1}$ regions with resolution of $4 \mathrm{~cm}^{-1}$. Nuclear magnetic resonance (NMR) spectra were recorded on Varian $500 \mathrm{MHz}-\mathrm{NMR}$ Spectrometer. The synthesized product was dissolved in methanol-d4 and the chemical shifts were given on the parts per million scales with TMS as an internal standard.

\section{Abbreviations \\ ANOVA: analysis of variance; CCD: central composite design; D: desirability; DHCA: dihydrocaffeic acid; DMSO: dimethyl sulfoxide; DTGS: deuterated triglycine sulphate; ILs: ionic liquids; NMR: nuclear magnetic resonance; FTIR: Fourier transforms infra-red.}

\section{Authors' contributions}

SG carried out all the experiments, data analysis and interpretations. OL, CP, FA and SW have critically reviewed the content of this manuscript. OL has made intellectual contributions and given the final approval for the manuscript to be published. All authors read and approved the final manuscript.

\begin{abstract}
Author details
1 Department of Food Technology, University Putra Malaysia, 43400 Serdang, Selangor, Malaysia. ${ }^{2}$ Department of Food Science, University Putra Malaysia, 43400 Serdang, Selangor, Malaysia. ${ }^{3}$ Laboratory of Natural Products, Institute of Bioscience, University Putra Malaysia, 43400 Serdang, Selangor, Malaysia.
\end{abstract}

\section{Acknowledgements}

This study was supported by University Putra Malaysia Research Grant No: 5524558.

\section{Competing interests}

The authors declare that they have no competing interests.

\section{Publisher's Note}

Springer Nature remains neutral with regard to jurisdictional claims in published maps and institutional affiliations.
Received: 16 August 2016 Accepted: 23 May 2017

Published online: 26 May 2017

\section{References}

1. Decker E (1998) Strategies for manipulating the prooxidative/antioxidative balance of foods to maximize oxidative stability. Trends Food Sci Technol 9:241-248

2. Figueroa-Espinoza M-C, Villeneuve P (2005) Phenolic acids enzymatic lipophilization. J Agric Food Chem 53:2779-2787

3. Khadem S, Marles RJ (2010) Monocyclic phenolic acids; hydroxy-and polyhydroxybenzoic acids: occurrence and recent bioactivity studies. Molecules 15:7985-8005

4. Gauthier L, Verdal M-N, Marchegay G, Pinson-Gadais L, Ducos C, RichardForget F, Atanasova-Penichon V (2016) Fungal biotransformation of chlorogenic and caffeic acids by Fusarium graminearum: new insights in the contribution of phenolic acids to resistance to deoxynivalenol accumulation in cereals. Int J Food Microbiol 221:61

5. Lu Y, Luthria D (2016) Influence of gelatinization on the extraction of phenolic acids from wheat fractions. Food Chem 194:1138-1142

6. Pietta P-G (2000) Flavonoids as antioxidants. J Nat Prod 63:1035-1042

7. Huang W-Y, Cai Y-Z, Zhang Y (2009) Natural phenolic compounds from medicinal herbs and dietary plants: potential use for cancer prevention. Nutr Cancer 62:1-20

8. Ingraham LL, Corse J (1951) Enzymatic browning of fruits. I. Autoxidation of chlorogenic acid. J Am Chem Soc 73:5550-5553

9. Katsoura M, Polydera A, Tsironis L, Tselepis A, Stamatis H (2006) Use of ionic liquids as media for the biocatalytic preparation of flavonoid derivatives with antioxidant potency. J Biotechnol 123:491-503

10. Eastoe J, Gold S, Rogers SE, Paul A, Welton T, Heenan RK, Grillo I (2005) Ionic liquid-in-oil microemulsions. J Am Chem Soc 127:7302-7303

11. Couling DJ, Bernot RJ, Docherty KM, Dixon JK, Maginn EJ (2006) Assessing the factors responsible for ionic liquid toxicity to aquatic organisms via quantitative structure-property relationship modeling. Green Chem 8:82-90

12. Zhao D, Liao Y, Zhang Z (2007) Toxicity of ionic liquids. Clean Soil Air Water 35:42-48

13. De Diego T, Lozano P, Gmouh S, Vaultier M, Iborra JL (2005) Understanding structure-stability relationships of candida a ntartica lipase $b$ in ionic liquids. Biomacromol 6:1457-1464

14. Kaar JL, Jesionowski AM, Berberich JA, Moulton R, Russell AJ (2003) Impact of ionic liquid physical properties on lipase activity and stability. J Am Chem Soc 125:4125-4131

15. Kim M-J, Choi MY, Lee JK, Ahn Y (2003) Enzymatic selective acylation of glycosides in ionic liquids: significantly enhanced reactivity and regioselectivity. J Mol Catal B Enzym 26:115-118

16. Lozano P, De Diego T, Carrie D, Vaultier M, Iborra J (2001) Over-stabilization of Candida antarctica lipase B by ionic liquids in ester synthesis. Biotech Lett 23:1529-1533

17. Persson M, Bornscheuer UT (2003) Increased stability of an esterase from Bacillus stearothermophilus in ionic liquids as compared to organic solvents. J Mol Catal B Enzym 22:21-27

18. Park S, Kazlauskas RJ (2001) Improved preparation and use of roomtemperature ionic liquids in lipase-catalyzed enantio- and regioselective acylations. J Organ Chem 66:8395-8401

19. Park S, Kazlauskas RJ (2003) Biocatalysis in ionic liquids_advantages beyond green technology. Curr Opin Biotechnol 14:432-437

20. Van Rantwijk F, Sheldon RA (2007) Biocatalysis in ionic liquids. Chem Rev 107:2757-2785

21. Yang Z, Feddern V, Glasius M, Guo Z, Xu X (2011) Improved enzymatic production of phenolated acylglycerols through alkyl phenolate intermediates. Biotech Lett 33:673-679

22. Yang Z, Pan W (2005) lonic liquids: green solvents for nonaqueous biocatalysis. Enzym Microb Technol 37:19-28

23. Miyake Y, Yamamoto K, Osawa T (1997) Metabolism of antioxidant in lemon fruit by human intestinal bacteria. J Agric Food Chem 45:3738

24. Lasekan O, Salva TJ, Abbas K (2009) Effect of malting conditions and quality characteristics of malt and roasted malt extract from 'acha' grains (Digitaria exilis Stapf). J Sci Food Agric 90:850-860 
25. Xin J-Y, Zhang L, Chen L-L, Zheng Y, Wu X-M, Xia C-G (2009) Lipasecatalyzed synthesis of ferulyl oleins in solvent-free medium. Food Chem 112:640-645

26. Gardas RL, Coutinho JA (2008) A group contribution method for viscosity estimation of ionic liquids. Fluid Phase Equilib 266:195-201

27. Liu L, Jin C, Zhang Y (2014) Lipophilic phenolic compounds (Lipo-PCs): emerging antioxidants applied in lipid systems. RSC Adv 4:2879-2891

28. Tan Z, Shahidi F (2012) Optimization of enzymatic synthesis of phytosteryl caprylates using response surface methodology. J Am Oil Chem Soc 89:657-666

29. Joglekar A, May A (1987) Product excellence through design of experiments. Cereal Foods World 32:857

30. Montgomery DC, Runger GC, Hubele NF (2009) Engineering statistics. Wiley, Hoboken

31. Mason RL, Gunst RF, Hess JL (2003) Statistical design and analysis of experiments: with applications to engineering and science, vol 474 Wiley, Hoboken

32. Vining GG, Kowalski S (2010) Statistical methods for engineers. Cengage Learning, Boston

33. Myers RH, Montgomery DC, Anderson-Cook CM (2016) Response surface methodology: process and product optimization using designed experiments. Wiley, Hoboken

34. Lee J, Ye L, Landen WO, Eitenmiller RR (2000) Optimization of an extraction procedure for the quantification of vitamin $\mathrm{E}$ in tomato and broccoli using response surface methodology. J Food Compos Anal 13:45-57
35. Weng W-L, Liu Y-C, Lin C-W (2001) Studies on the optimum models of the dairy product Kou Woan Lao using response surface methodology. Asian Australas J An Sci 14:1470-1476

36. Floros J, Chinnan M (1988) Computer graphics- assisted optimization for product and process development. Food Technol 42:72-78

37. Giovanni M (1983) Response surface methodology and product optimization. Food Technol 37(11):41-45

38. Lasekan O (2011) Headspace solid-phase microextraction analysis of the volatile flavour compounds of roasted chickpea (Cicer arietinum L.). J Food Process Technol 2:1

39. Borneman WS, Hartley RD, Morrison WH, Akin DE, Ljungdahl LG (1990) Feruloyl and p-coumaroyl esterase from anaerobic fungi in relation to plant cell wall degradation. Appl Microbiol Biotechnol 33:345-351

40. Nagaoka T, Banskota AH, Tezuka Y, Saiki I, Kadota S (2002) Selective antiproliferative activity of caffeic acid phenethyl ester analogues on highly liver-metastatic murine colon 26-L5 carcinoma cell line. Bioorg Med Chem 10:3351-3359

41. Yang Z, Guo Z, Xu X (2012) Ionic liquid-assisted solubilization for improved enzymatic esterification of phenolic acids. J Am Oil Chem Soc 89:1049-1055

\section{Submit your manuscript to a SpringerOpen ${ }^{\circ}$ journal and benefit from:}

- Convenient online submission

- Rigorous peer review

- Immediate publication on acceptance

- Open access: articles freely available online

- High visibility within the field

- Retaining the copyright to your article 